\title{
PHOTOCATALYTIC INACTIVATION OF BACTERIA IN WATER USING SUSPENDED AND IMMOBILIZED SILVER-TiO
}

Rafael van Grieken, Javier Marugán*, Carlos Sordo, Patricia Martínez, Cristina Pablos.

Department of Chemical and Environmental Technology, ESCET, Universidad Rey Juan Carlos, C/ Tulipán s/n, 28933 Móstoles (Madrid), Spain,

* Tel: +34 91664 7466, Fax +34 91488 7068, E-mail: javier.marugan@urjc.es

Published on

Applied Catalysis B: Environmental, 93: 112-118 (2009)

doi:10.1016/j.apcatb.2009.09.019 


\begin{abstract}
Incorporation of silver to titanium dioxide is of great interest for photocatalytic disinfection applications since in addition to the enhancement of the electron-hole separation and interfacial charge transfer and the increase in the visible light response, silver compounds present a strong bactericidal effect. $\mathrm{Ag} / \mathrm{TiO}$ materials used in suspension and immobilized in two different configurations (catalytic wall and fixed-bed reactors) have been prepared, characterized and tested using Escherichia coli as model microorganism. Although the incorporation of silver to powdered Degussa P25 $\mathrm{TiO}_{2}$ increases the activity, the thermal treatment required for the stabilization of the supported metal particles reduces the global efficiency. The comparison with experiments of dye photodegradation indicates that the activity of $\mathrm{Ag} / \mathrm{TiO}_{2}$ is mainly due to the bactericidal role of silver and not to the enhancement of the photocatalytic mechanism. The best tested system has been proved to be the $\mathrm{Ag} / \mathrm{TiO}_{2}$ catalytic wall reactor with a $0.6 \mathrm{wt} \%$ of Ag loading, showing a high activity both in relative (per gram of $\mathrm{TiO}_{2}$ ) and absolute terms, an optimal use of the radiation source, and a good stability of the film with negligible silver lixiviation, allowing the continuous treatment of water.
\end{abstract}

KEYWORDS: photocatalysis, disinfection, silver, E.coli, immobilized $\mathrm{TiO}_{2}$ 


\section{Introduction}

Oxidation technologies such as chlorination and ozonation have long been used for the disinfection of water. However, several concerns have emerged regarding these treatments, mainly due to the formation of potentially harmful disinfection by-products such as trihalomethanes and haloacetic acids upon reaction with the naturally occurring organic mater and halide ions [1-3].

Advanced oxidation processes (AOP) have been extensively investigated for the treatment of wastewater [4-6]. Among them, $\mathrm{TiO}_{2}$ photocatalysis has emerged as a promising alternative technology for the disinfection of water with purposes of drinking water supply or reuse of wastewater plants effluents [7-8]. In addition to the high photostability and low cost of the catalyst, the heterogeneous photocatalytic technologies have several advantages over other AOPs such as working under ambient conditions of temperature and pressure, the use of air as oxidant reactant, and the possibility of using solar light to drive the process, all items very interesting from the energy consumption and environmental impact viewpoints.

One of the main drawbacks of $\mathrm{TiO}_{2}$ photocatalysis is the relatively high band gap energy of the semiconductor (above $3.0 \mathrm{eV}$ for rutile and $3.2 \mathrm{eV}$ for anatase, corresponding to UV-A radiation) what limits the absorption of light to only approximately $3-5 \%$ of the solar spectrum [9]. In addition to that, the quantum yield of the process is in the order of $4 \%$ [10] what means that only 1 of every 25 electron-hole pairs generated upon radiation absorption are successfully leading to the desired reaction, whereas the remaining recombine releasing heat. For those reasons, important research efforts have been devoted to the improvement of the photocatalytic efficiency by doping or metallization of the catalyst surface [11-12]. Among the metallic species usually incorporated to $\mathrm{TiO}_{2}$ surface, silver has shown an enhancement of the electron-hole separation and interfacial charge transfer [13-14], increasing the visible light excitation of $\mathrm{TiO}_{2}$ [15]. In addition to that, the strong bactericidal power of silver compounds makes $\mathrm{Ag} / \mathrm{TiO}_{2}$ materials very attractive to explore the potential in photocatalytic disinfection applications, as confirmed by the enhancement for the photocatalytic inactivation of microorganisms reported by several research groups upon incorporation of silver into the catalysts [16-19]. The mechanism of the silver toxicity is still unclear, being suggested the possible alteration of the membranes properties through the 
degradation of lipopolysaccharide molecules and the subsequent increase in the membrane permeability or the damage of the DNA [20].

On the other hand, another important limitation of the photocatalytic technologies using titanium dioxide suspensions is the need of a post-treatment separation stage [21-22]. Consequently, the treatment of water in continuous reactors require the development of immobilised $\mathrm{TiO}_{2}$ systems to avoid the recovery stage and the losses of catalyst [23], being this aspect particularly important when silver or other expensive metals have been incorporated into the $\mathrm{TiO}_{2}$ [24]. However, the use of immobilized photocatalysts usually introduces mass transport limitations that reduce the global efficiency of the reaction, a feature that could be particularly significant in disinfection processes due to the high size of microorganisms [25]. Moreover, the adhesion between bacteria and catalyst has been shown to play a crucial role on the efficiency of the process [26-28].

This work is focused on the development of $\mathrm{Ag} / \mathrm{TiO}{ }_{2}$ materials with enhanced photocatalytic efficiency for the disinfection of water. Two different silver-modified titania immobilised systems have been used (catalytic wall and fixed-bed reactors), comparing their activity with that corresponding to powder $\mathrm{Ag} / \mathrm{TiO}{ }_{2}$ in suspension and with bare $\mathrm{TiO}_{2}$. Escherichia coli has been selected as model microorganism, due to its wide use as indicator of faecal contamination.

\section{Experimental}

\subsection{Photoreactor}

The photocatalytic experiments have been carried out in the experimental setup schematized in Figure 1. The annular photoreactor $(15 \mathrm{~cm}$ long, $3 \mathrm{~cm}$ inner diameter and 5 $\mathrm{cm}$ outer diameter) operates in a closed circuit with a reservoir tank, recirculating at $2.5 \mathrm{~L}$ $\min ^{-1}$ of flow rate, being the total working volume of $1 \mathrm{~L}$. A Philips TL6-W black light with an emission maximum at $365 \mathrm{~nm}$ was placed in the axis of the annulus to irradiate the reactor with a stationary UV-A incident photon flow of $2.8 \times 10^{-6}$ Einstein s$^{-1}$ (calculated by ferrioxalate actinometry). In all cases, the lamp was switched on 15 min before the reaction starts to stabilize its emission power and spectrum. 


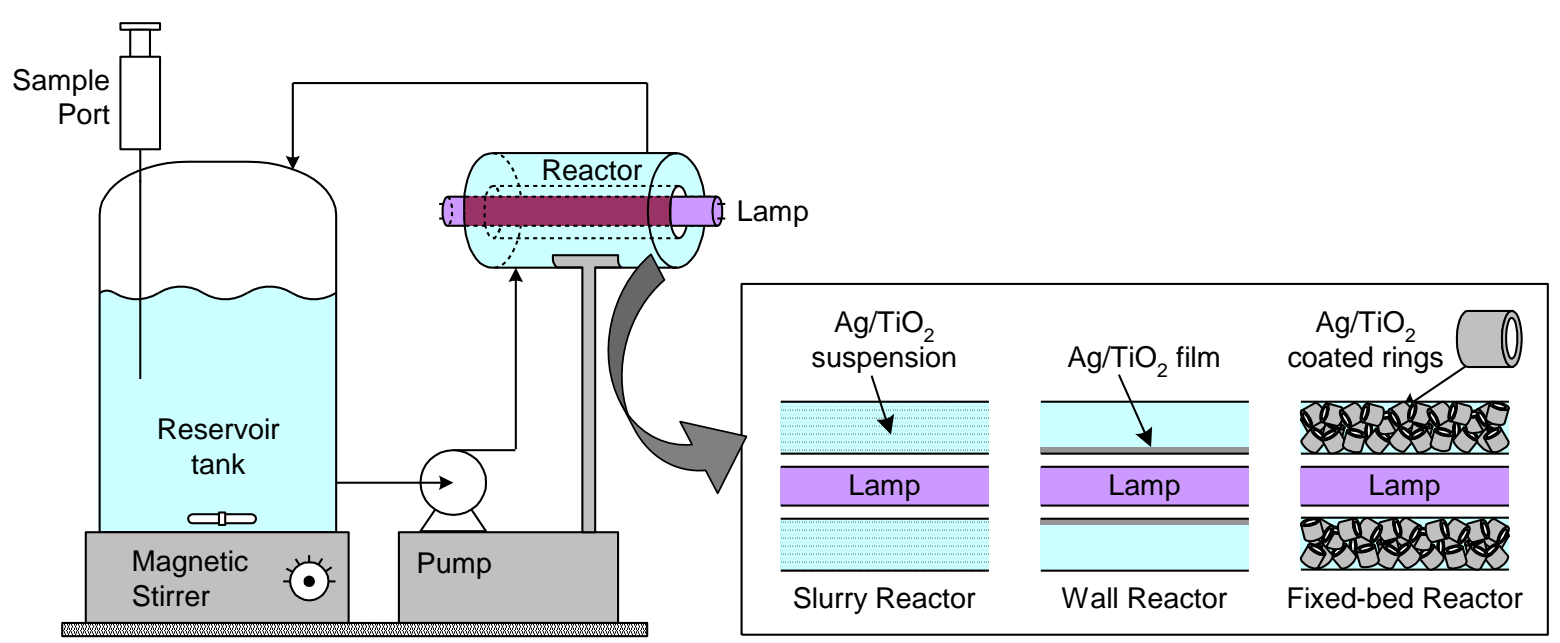

Figure 1. Experimental setup used for the photocalytic reactions (see text for details).

The $\mathrm{Ag} / \mathrm{TiO}_{2}$ photocatalysts were tested in three different reactor configurations previously tested using pure $\mathrm{TiO}_{2}$ photocatalysts [23] to investigate the role on the photocatalytic reaction of the silver incorporated into the materials:

i) Slurry reactor, in which the $0.1 \mathrm{~g} \mathrm{~L}^{-1} \mathrm{Ag} / \mathrm{TiO}_{2}$ particles are suspended in the whole liquid volume of the recirculation system. This catalysts concentration has been selected as optimum according to previous studies with pure $\mathrm{TiO}_{2}$ suspensions [23].

ii) Wall reactor, in which the $\mathrm{Ag} / \mathrm{TiO}_{2}$ photocatalyst is immobilized as a film in the inner-tube wall of the annular photoreactor.

iii) Fixed-bed reactor, in which glass rings coated with the $\mathrm{Ag} / \mathrm{TiO}_{2}$ material are placed in the whole annular reactor volume.

\subsection{Catalysts preparation and characterization}

Degussa P25 titanium dioxide was immobilized onto the glass substrates by a dipcoating procedure schematized in Figure 2. All the materials used in the present work have been prepared following three coating cycles. More details of the method can be found elsewhere [23]. 


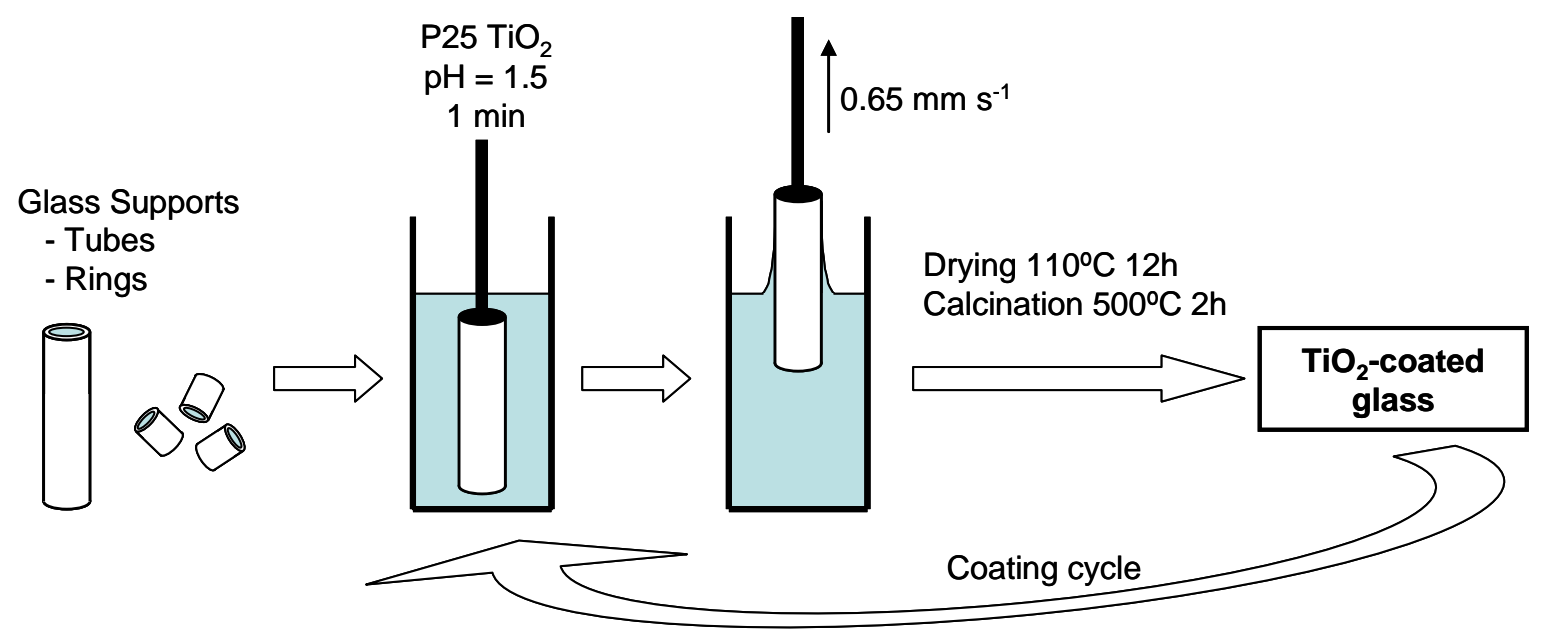

Figure 2. Schematic representation of the immobilization of $\mathrm{TiO}_{2}$ onto the glass supports.

The incorporation of silver was carried out by photocatalytic reduction of $1 \mathrm{~L}$ of silver nitrate (Scharlab) solutions with the desired concentration, adding $1 \mathrm{~mL}$ of 2-propanol (Scharlab) as sacrificial organic acting as hole/hydroxyl radical scavenger. The photodeposition reactions were performed in the same experimental setup described above, using the titania in suspension or immobilized as wall or fixed-bed in the photoreactor. Irradiation with the UV-A lamp lasted for $2 \mathrm{~h}$, enough to achieve the total reduction of the silver, as confirmed by the evolution of the silver remaining in solution analyzed by inductively coupled plasma atomic emission spectroscopy (ICP-AES) in a Varian Vista AX equipment. Concentration of silver was quantified using the spectral line at $328.068 \mathrm{~nm}$ after calibration with certified standards. If not otherwise specified, the $\mathrm{Ag} / \mathrm{TiO}_{2}$ materials were dried at $110^{\circ} \mathrm{C}$ and calcined at $400^{\circ} \mathrm{C}$ for $6 \mathrm{~h}$ to assure the fixation of silver to the $\mathrm{TiO}_{2}$ surface [16]. Immobilized $\mathrm{Ag} / \mathrm{TiO}_{2}$ photocatalysts were directly used in the photocatalytic tests after calcination, whereas powder $\mathrm{Ag} / \mathrm{TiO}_{2}$ was finely ground before being suspended.

The amount of silver incorporated to the materials was also evaluated by ICP-AES after treating the materials with nitric acid, being in all cases in agreement with the nominal silver content estimated from the amount of silver nitrate initially dissolved. Micrographs of the silver nanoparticles incorporated to the $\mathrm{TiO}_{2}$ surface were taken on a Nova NanoSEM230 ultra-high resolution field emission scanning electron microscope (FESEM) equipped with an energy dispersive X-ray spectroscopy (EDS) microanalysis probe with a superultrathin window (SUTW). Both a Everhart-Thornley secondary electron detector 
(ETD) and a low-voltage high-contrast solid state detector (vCD) have been used to obtained textural and compositional information, respectively. The specific surface areas of the powder materials were calculated according to the Brunauer-Emmett-Teller (BET) method from the nitrogen adsorption-desorption isotherms at $77 \mathrm{~K}$ recorded in a Micromeritics Tristar 3000 equipment. UV-vis transmission spectra of the immobilized systems were acquired in a Varian Cary 500 Scan UV-vis-NIR spectrophotometer.

\subsection{Photocatalytic experiments}

Lyophilized Escherichia coli K-12 strains provided by the Spanish Type Culture Collection (CECT 4624, corresponding to ATCC 23631) were used as model microorganisms for the disinfection experiments. Fresh bacterial cultures of around $10^{9} \mathrm{CFU} \mathrm{mL}^{-1}$ of stationary concentration were prepared by inoculation of $20 \mathrm{~mL}$ of Luria-Bertani nutrient medium (Miller's LB Broth, Scharlab) and aerobic incubation at $37{ }^{\circ} \mathrm{C}$ under rotary shaking for $24 \mathrm{~h} .5 \mathrm{~mL}$ of this culture were centrifuged and rinsed twice with sterile ultra-pure water (Milli-Q®, $18.2 \mathrm{M} \Omega \mathrm{cm}$ ) before diluting $1 \mathrm{~mL}$ of the resultant bacterial suspension to $1 \mathrm{~L}$ to prepare the reacting suspension, with an initial concentration of viable bacteria around $10^{6}$ $\mathrm{CFU} \mathrm{mL}^{-1}$.

Reactions started just after adding the catalyst to the suspension (for powder $\mathrm{Ag} / \mathrm{TiO}_{2}$ ) and switching on the recirculation pump. No equilibration time has been considered for the system, assuming that the decrease in bacterial concentration due to dark adsorption could be neglected in comparison with the bactericidal properties of silver nanoparticles. The evolution of the reaction has been followed quantifying the concentration of viable bacteria by a standard serial dilution method using LB nutrient agar plates (Miller's LB Agar, Scharlab). Eight replicates of each decimal dilution were incubated at $37^{\circ} \mathrm{C}$ for $24 \mathrm{~h}$ before counting the number of bacterial colonies. Lixiviation of silver from the $\mathrm{Ag} / \mathrm{TiO}{ }_{2}$ to the solution has been quantified by ICP-AES.

Experiments of photocatalytic degradation of methylene blue (Sigma-Aldrich) $20 \mu \mathrm{M}$ aqueous solutions were carried out in order to discriminate the bactericidal role of silver from the enhancement of the photocatalytic process. Reactions were followed through the decrease in the absorption of the solution at $664 \mathrm{~nm}$. 


\section{Results and discussion}

\section{1. $\mathrm{Ag} / \mathrm{TiO}_{2}$ in suspension}

Figure 3 shows the results obtained in the photocatalytic inactivation of $E$. coli with $0.1,0.5$ and $1.0 \mathrm{wt} \% \mathrm{Ag} / \mathrm{TiO}_{2}$ powders in suspension. The bactericidal efficiency is clearly enhanced for increasing silver loading but in all cases the activity seems to be lower than that observed for the bare $\mathrm{TiO}_{2}$.

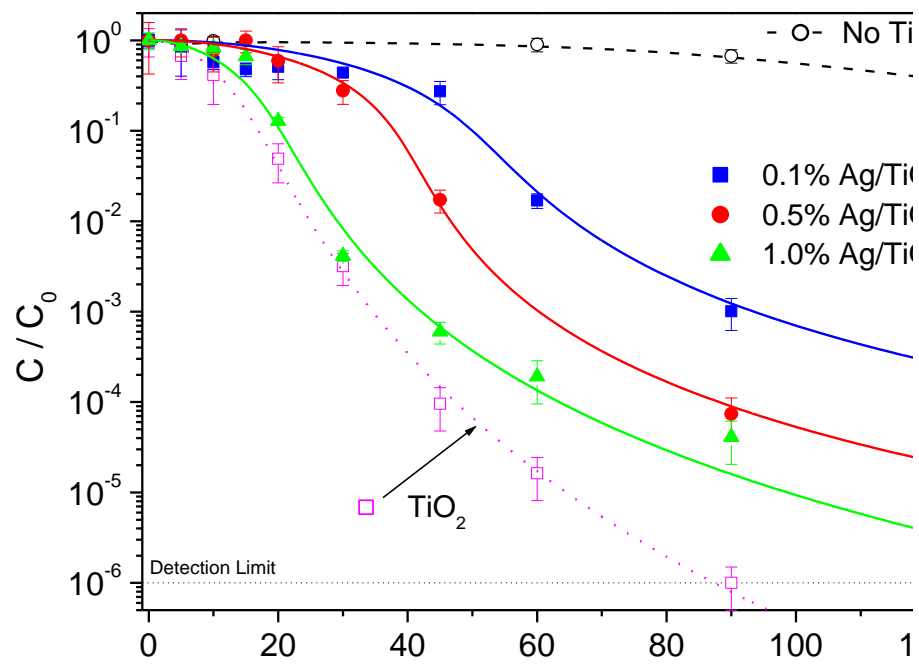

Figure 3. Effect of silver loading on the photocatalytic inactivation of $E$. coli in water using $\mathrm{TiO}_{2}$ and $\mathrm{Ag} / \mathrm{TiO}_{2}$ in suspension. Fitting lines were calculated using a kinetic model based on a series events disinfection mechanism [25]. Error bars calculated from eight independent bacteria counting measurements.

These results contrast with some of the reports existing in the literature showing an increase in the $E$. coli photocatalytic inactivation efficiency of $\mathrm{TiO}_{2}$ upon silver incorporation [16-18]. The catalysts used in these papers were: i) commercial anatase $\mathrm{TiO}_{2}$ (Aldrich) following a thermal treatment to incorporate the silver [16]; ii) Degussa $\mathrm{P} 25 \mathrm{TiO}_{2}$ used directly after silver photodeposition without further thermal treatment [17]; and iii) a homemade $\mathrm{TiO}_{2}$ used in which silver incorporation is produced by either impregnation and thermal 
treatment or direct photodeposition [18]. It must be noticed that the combination of base $\mathrm{TiO}_{2}$ materials and preparation route of the silver-modified photocatalysts is different in each paper and different from that used in the present work. To investigate the influence of the thermal treatment on the activity of the materials, additional experiments of photocatalytic inactivation with calcined $\mathrm{TiO}_{2}$ (following the same preparation procedure but without silver salt addition) and with uncalcined $1.0 \% \mathrm{Ag} / \mathrm{TiO}_{2}$ (following the same preparation procedure but without thermal treatment) were carried out. The results are displayed in Figure 4.

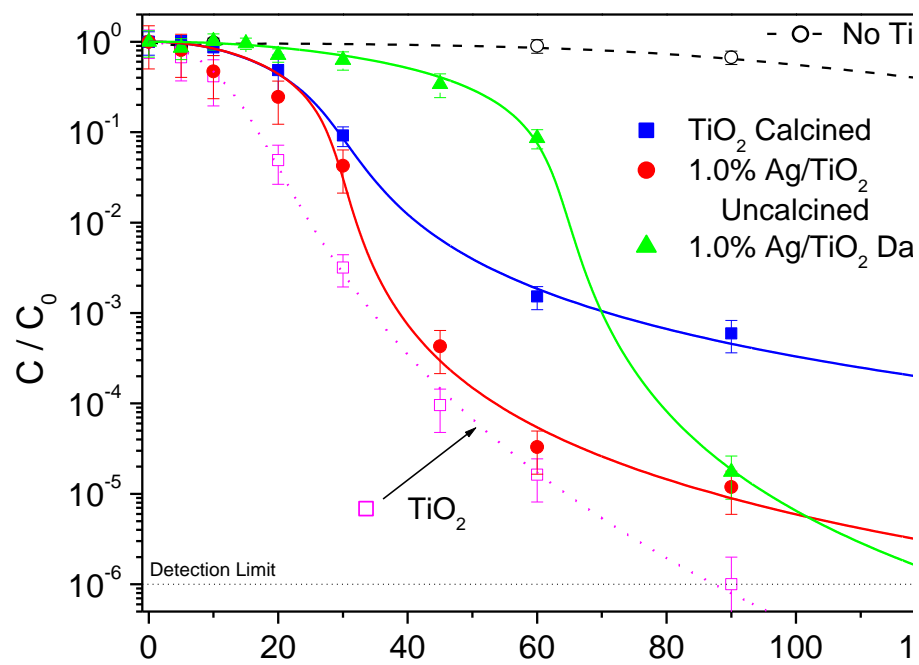

Figure 4. Effect of calcination and dark disinfection on the photocatalytic inactivation of $E$. coli in water using $\mathrm{TiO}_{2}$ and $\mathrm{Ag} / \mathrm{TiO}_{2}$ in suspension. Fitting lines were calculated using a kinetic model based on a series events disinfection mechanism [25]. Error bars calculated from eight independent bacteria counting measurements.

The activity of the Degussa $\mathrm{P} 25$ bare $\mathrm{TiO}_{2}$ substantially decreases after calcination. Moreover, taking as reference the activity of this calcined $\mathrm{TiO}_{2}$ material, the incorporation of silver does enhances the photocatalytic efficiency of the material, being more active as the silver content increases from $0.1 \%$ to $1.0 \mathrm{wt} \%$, in agreement with the results in the literature. Consequently, it can be assumed that the decrease in the activity is derived from the thermal treatment and not from the incorporation of silver. A preliminary explanation for this effect could be a decrease in the specific surface area of the catalysts during calcination.

Characterization of the samples shows that the BET specific surface area $\left(S_{B E T}\right)$ of the material decreases from $52 \mathrm{~m}^{2} \mathrm{~g}^{-1}$ of the commercial $\mathrm{P} 25 \mathrm{TiO}_{2}$ to $42 \mathrm{~m}^{2} \mathrm{~g}^{-1}$ after calcination. 
In agreement with other reports [18], incorporation of silver does not seem to affect the textural properties of the material, having all the calcined $\mathrm{Ag} / \mathrm{TiO}{ }_{2}$ samples comparable specific surface areas $\left(42.2 \pm 1.0 \mathrm{~m}^{2} \mathrm{~g}^{-1}\right)$ whereas uncalcined $1.0 \% \mathrm{Ag} / \mathrm{TiO}_{2}$ maintains $51 \mathrm{~m}^{2}$ $\mathrm{g}^{-1}$ of $S_{B E T}$. In any case, this reduction of the textural properties of $\mathrm{TiO}_{2}$ does not seem to be enough to justify the decrease in the activity of the catalysts upon calcination, being also caused by the dehydroxylation of the titania surface, as proposed by Fernandes Machado and Santana [29].

Results of bacterial inactivation with uncalcined $1.0 \% \mathrm{Ag} / \mathrm{TiO}_{2}$ (Figure 4) do not apparently confirm the decrease in the activity produced by the thermal treatment in the case of silver-modified titanium dioxide materials, showing similar activity to the corresponding calcined $1.0 \% \mathrm{Ag} / \mathrm{TiO}_{2}$ catalyst, and lower than that of bare $\mathrm{P} 25 \mathrm{TiO}_{2}$. This suggests that the incorporation of silver induce a decrease in the activity not only derived of the calcination. Figure 4 also displays the results of bacterial inactivation with calcined $\mathrm{Ag} / \mathrm{TiO}_{2}$ in the dark. Surprisingly, after a longer initial delay the activity is comparable to that observed under irradiation and higher than that shown by the calcined $\mathrm{TiO}_{2}$ material. The explanation of these unexpected results was found on the high concentration of silver lixiviated to the solution measured by ICP-AES (above $50 \%$ of the silver loading at the end of the reaction). Similar silver lixiviation values were measured in the experiment with uncalcined $\mathrm{Ag} / \mathrm{TiO}$, whereas only $15 \%$ of the silver was lixiviated when using the calcined $\mathrm{Ag} / \mathrm{TiO}$ 2 material. As a consequence, only the calcined $\mathrm{Ag} / \mathrm{TiO}_{2}$ material could be considered as partially reusable. Moreover, such high values of silver in solution suggest that the disinfection profiles could not be linked exclusively to pure photocatalytic process but from the well-known bactericidal properties of silver [20]. Summarizing, despite the decrease in the global activity observed after silver incorporation, it seems that calcination stabilizes the silver deposits and increase the pure photocatalytic activity of the material in comparison with the uncalcined $\mathrm{Ag} / \mathrm{TiO}{ }_{2}$ material, whose lower activity is probably counteracted by its higher silver lixiviation.

To discriminate between the bactericidal role of silver and the enhancement of the photocatalytic process, additional experiments of photocatalytic degradation of methylene blue solutions were carried out (Figure 5). In this case, the decrease in the activity of the bare $\mathrm{TiO}_{2}$ after calcination is even more pronounced than that shown in the disinfection experiments. Moreover, incorporation of silver further reduced the activity, probably due to detrimental effects derived from excessive silver loading, as will be discussed later. In any 
case, these results confirm that the observed bacterial inactivation should be substantially attributed to the bactericidal role of silver.

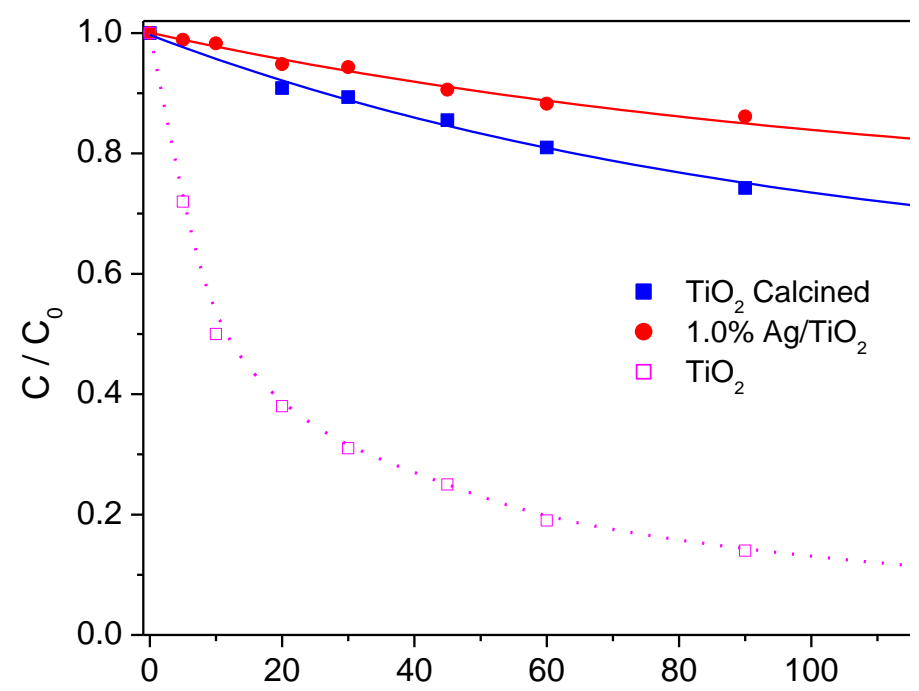

Figure 5. Photocatalytic degradation of methylene blue solutions using $\mathrm{TiO}_{2}$ and $\mathrm{Ag} / \mathrm{TiO}{ }_{2}$ in suspension.

\subsection{Immobilized $\mathrm{Ag} / \mathrm{TiO}_{2}$ catalytic systems: wall and fixed-bed reactor}

Immobilized $\mathrm{Ag} / \mathrm{TiO}_{2}$ systems with increasing silver loadings have been prepared by photoreduction of $\mathrm{AgNO}_{3}$ solutions, quantifying the amount of deposited silver by ICP-AES. Figure 6 displays the photographs of the reactor inner wall coated with $\mathrm{TiO}_{2}$ and $\mathrm{Ag} / \mathrm{TiO}{ }_{2}$. It can be seen that incorporation of high amounts of silver darkens the tube. In fact, UV-vis transmission spectra (not shown) confirm that this highly loaded $\mathrm{Ag} / \mathrm{TiO}_{2}$ tube present negligible transmittance in the whole studied wavelength range from $300 \mathrm{~nm}$ to $800 \mathrm{~nm}$, whereas $\mathrm{TiO}_{2}$ tubes only absorb in the UV-A range. This visible light response of $\mathrm{Ag} / \mathrm{TiO}{ }_{2}$ can be attributed to the characteristic silver surface plasmon band, indicative of the formation of nanometer sized silver metal [15]. 


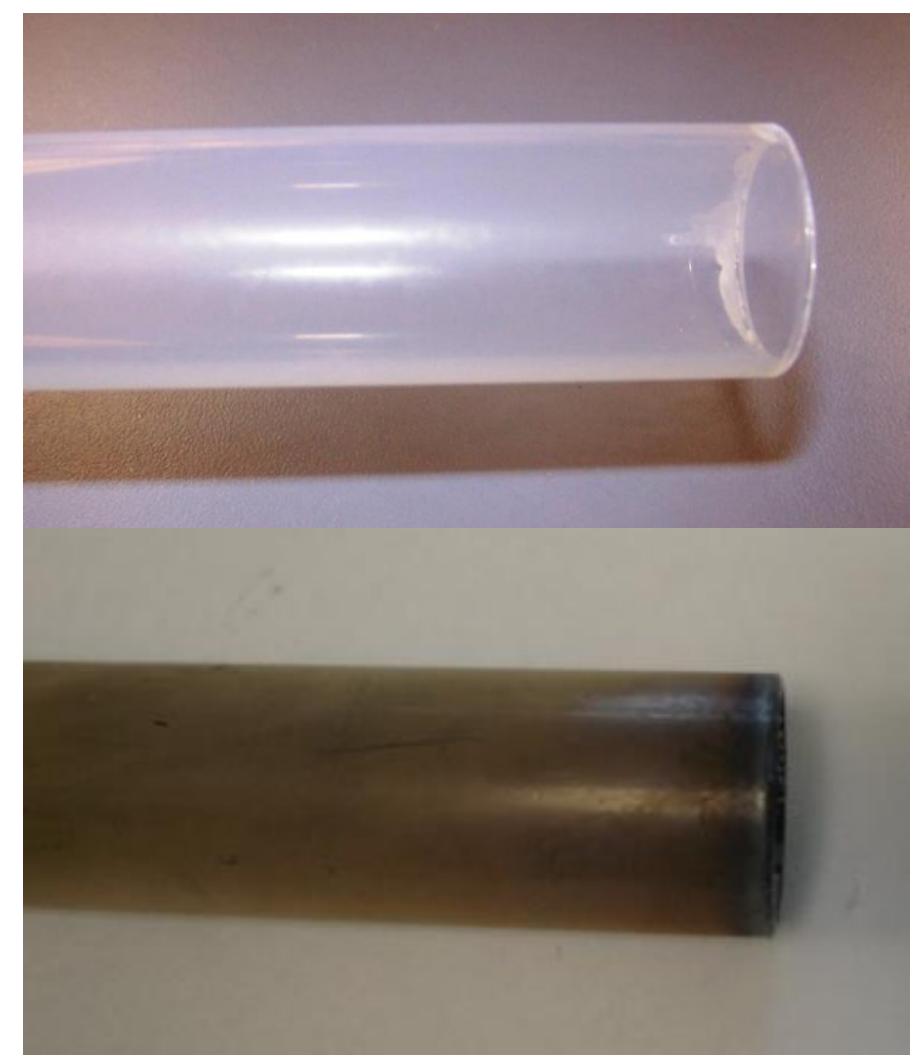

Figure 6. Photographs of the $\mathrm{TiO}_{2}$ and $\mathrm{Ag} / \mathrm{TiO}_{2}$ photocatalytic wall systems.

Electron micrographs of the immobilized $\mathrm{Ag} / \mathrm{TiO}_{2}$ surface are displayed in Figure 7. First micrograph, taken with the ETD detector, shows the particulate nature of the $\mathrm{TiO}_{2}$ film, being this roughness favourable for the adhesion of bacteria. Second micrograph, taken with the $\mathrm{vCD}$ detector, emphasizes the differences in the atomic composition of the film, being attributed the brighter dots to the heavier atoms of silver. Finally, the third micrograph is a magnified view of the compositional image, in which the nanometric size of the bright clusters is clearly shown, being confirmed their silver composition by the EDS microanalysis. 


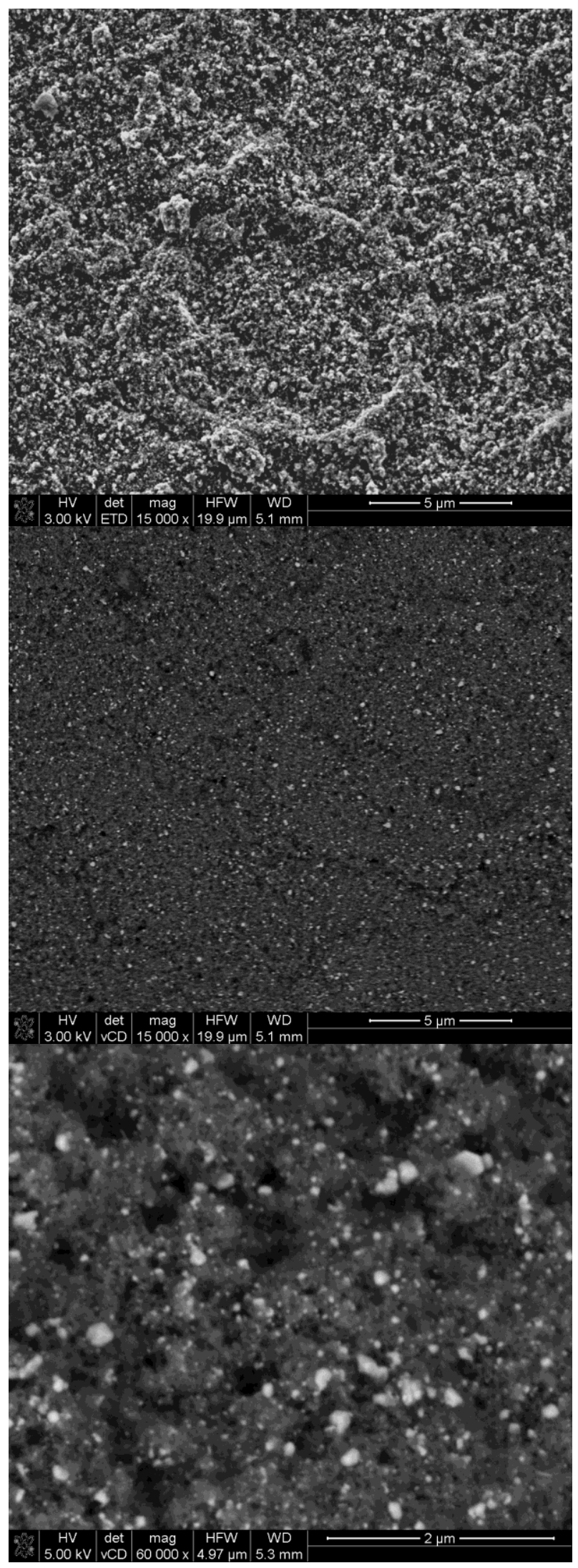

Figure 7. FESEM micrographs of the surface of the $\mathrm{Ag} / \mathrm{TiO}_{2}$ fixed-bed glass rings 
Bacterial inactivation profiles achieved with immobilized $\mathrm{Ag} / \mathrm{TiO}{ }_{2}$ wall reactors are shown in Figure 8. In all cases the inactivation is more effective than that obtained with the bare $\mathrm{TiO}_{2}$ tube, apparently being an optimum with a maximum efficiency for $0.6 \% \mathrm{wt} \%$ of silver loading.

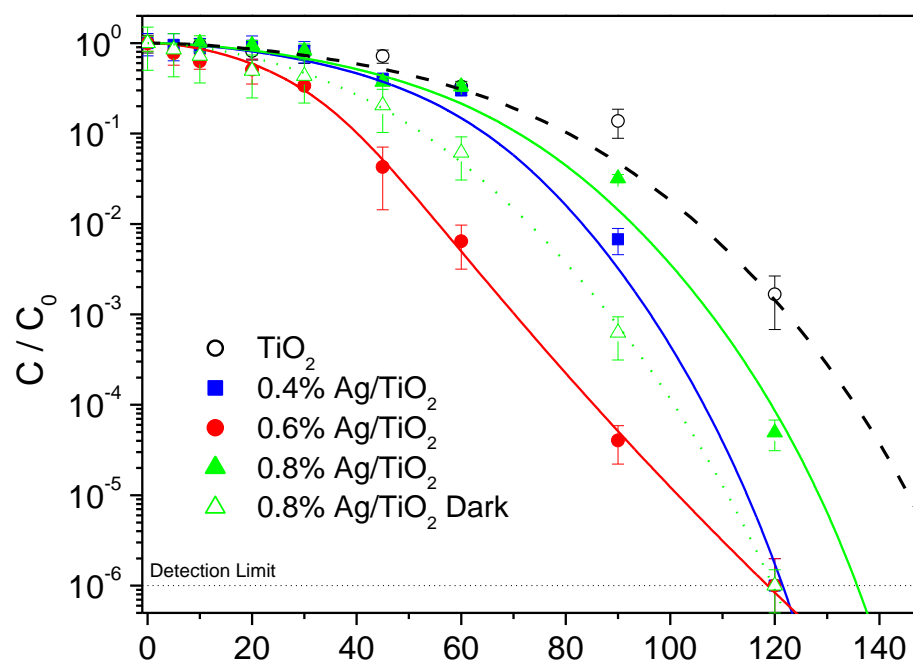

Figure 8. Photocatalytic inactivation of $E$. coli in water using $\mathrm{TiO}_{2}$ and $\mathrm{Ag} / \mathrm{TiO}{ }_{2}$ wall reactors. Fitting lines were calculated using a kinetic model based on a series events disinfection mechanism [25]. Error bars calculated from eight independent bacteria counting measurements.

Other research groups have reported the existence of an optimal silver loading [14,18, 30], although it has been stated that the correlation between photocatalytic activity and silver loading strongly depends on the preparation method [18] and the tested organic pollutant [3133]. The activity enhancement has been attributed not only to the electron sink role of the silver clusters but also to an improvement of the pollutant adsorption over the modified titania surface [34]. The dependence of the results with the specific tested pollutant has been justified through the different degradation mechanisms including hole trapping intermediates or the possibility of reductive degradation pathways [32-33]. Kubacka et al. [18] found evidences of the local-type modification of hydroxyl radicals formed upon light absorption in the neighbourhood of silver entities, being this property strongly related to the photokilling activity, more than changes in the adhesion of bacteria or the electron trapping role. On the other hand, high silver loadings show a detrimental effect on the activity. As reviewed by 
Tran et al. [31], a decrease in the activity of $\mathrm{Ag} / \mathrm{TiO}{ }_{2}$ materials for the mineralisation of organics in comparison with bare $\mathrm{TiO}_{2}$ has been observed by other researchers, justifying the detrimental effects by: $\mathrm{i}$ ) a reduction in the access of radiation to the $\mathrm{TiO}_{2}$ surface due to excessive surface coverage by the silver deposits; ii) blockage of the $\mathrm{TiO}_{2}$ active sites by the metal deposits which are necessary for the photocatalytic process; iii) an increase in charge carrier recombination rates at high silver loadings; and iv) a inhibition in the role of oxygen due to the preferential electron transfer from the $\mathrm{TiO}_{2}$ surface to the silver deposits.

Additionally, Kubacka et al. [18] suggest that silver can change the surface characteristics of titania, leading to measurable variations in the point of zero charge (PZC), modifying the adhesion between bacteria and catalyst, a critical point for the efficiency of the process [2628]. However, despite the large number of papers related to silver modification of titanium dioxide, only few research groups have studied the lixiviation of silver to check the stability of the silver deposits [18]. In all the experiments using irradiation, the analysis of silver in solution along the reaction shows a negligible lixiviation and a high stability of the surface silver deposits. In contrast, the results of the dark experiment with the $0.8 \% \mathrm{Ag} / \mathrm{TiO}_{2}$ tube show a substantial lixiviation of silver to the medium, justifying the increase in activity shown in Figure 8 by the higher bactericidal effect of soluble silver compounds. From dark experiments, both with the catalysts in suspension and the wall reactor, it can be concluded that radiation is an important factor to assure the stability of the Ag deposits, supplying the necessary electrons to maintain the silver in metallic state, whereas an important reoxidation takes place in dark.

Figure 9 shows the comparison of the photocatalytic inactivation of bacteria with both wall and fixed-bed reactors, using bare $\mathrm{TiO}_{2}$ and $0.6 \% \mathrm{Ag} / \mathrm{TiO}_{2}$. In both cases the incorporation of silver enhances the photokilling activity, being the effect much more pronounced in the immobilized wall reactor. In fact, whereas the time required to achieve the bacterial detection limit is quite similar for both bare $\mathrm{TiO}_{2}$ configurations and the $0.6 \%$ $\mathrm{Ag} / \mathrm{TiO}_{2}$ fixed-bed, it is substantially decreased by the use the $0.6 \% \mathrm{Ag} / \mathrm{TiO}{ }_{2}$ wall reactor. 


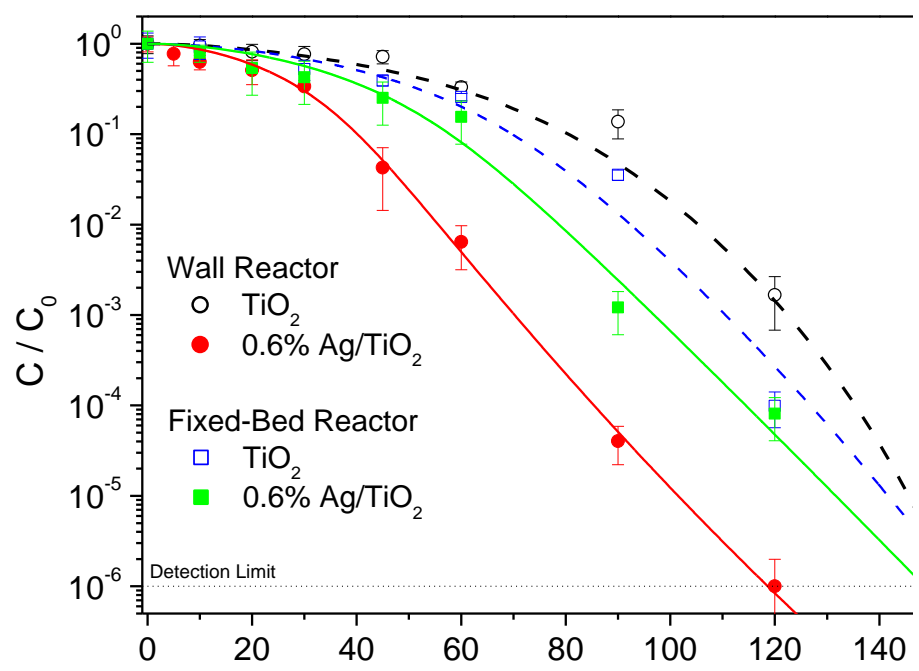

Figure 9. Comparison of the photocatalytic inactivation of $E$. coli in water using both wall and fixed-bed $\mathrm{TiO}_{2}$ and $\mathrm{Ag} / \mathrm{TiO}_{2}$ immobilized systems. Fitting lines were calculated using a kinetic model based on a series events disinfection mechanism [25]. Error bars calculated from eight independent bacteria counting measurements.

Analyzing the bacterial inactivation profiles showed in Figure 8 and 9, an important feature of these disinfection curves is that they do not show the characteristic ending tail that presents the disinfection experiments with catalyst in suspension represented in Figure 3 and 4 , reaching the bacterial detection limit during the log-linear region that appears after the initial delay of the curve. This fact has been previously observed for bare $\mathrm{TiO}_{2} \mathrm{immobilized}$ materials and attributed to a reduced competition of the organic residuals released to the medium upon the bacterial lysis for the photogenerated oxidant species [23]. Although the initial activity is clearly lower than those obtained with $\mathrm{TiO}_{2}$ slurries, the irradiation time required to reach the detection limit in the wall reactor at the optimal silver loading is not far from that required with bare $\mathrm{TiO}_{2}$ slurry and comparable to $\mathrm{Ag} / \mathrm{TiO}_{2}$ slurries. Consequently, in addition to the advantage related to the separation of the catalysts after the reaction, the immobilized systems seem to show a higher resistance to the inhibition by organic matter, a clear benefit for the disinfection of natural waters and effluents from wastewater treatment plants for reuse purposes.

From all the tested catalytic systems, it can be concluded that the $0.6 \% \mathrm{Ag} / \mathrm{TiO}_{2}$ wall reactor configuration is the most effective immobilized system for the bacterial inactivation. 
Moreover, considering that the amount of titanium dioxide incorporated to the tube is around $0.03 \mathrm{~g}$ [23] in comparison with $0.35 \mathrm{~g}$ loaded in the fixed-bed and the $0.1 \mathrm{~g} \mathrm{~L}^{-1}$ used in suspension, it is derived that the specific activity of the wall reactor is even higher than that of titanium dioxide in suspension. A possible explanation for this higher efficiency of the wall reactor is the differences existing in the titanium dioxide illumination pattern. Figure 10 schematizes how the absorption of photons of silver modified titanium dioxide in suspension takes place through the same surface in which silver has been deposited (the same is valid for the fixed-bed reactor configuration). In contrast, in the wall reactor the $\mathrm{TiO}_{2}$ film is irradiated from the surface adhered to the inner reactor glass tube wall, whereas silver has been deposited onto the external surface of the $\mathrm{TiO}_{2}$ film, in contact with the solution.

Consequently, silver deposits are not reducing the radiation flux reaching the titania surface, leading to an optimal configuration in which the radiation absorption is maximized whereas the electron trapping, the improvement of the bacterial adhesion and the direct bactericidal attack of silver is simultaneously achieved. Additionally, the wall reactor configuration avoids the existence of dark $\mathrm{Ag} / \mathrm{TiO}_{2}$ regions in the most external volume of the reactor, reducing the lixiviation of silver to the solution by reoxidation.

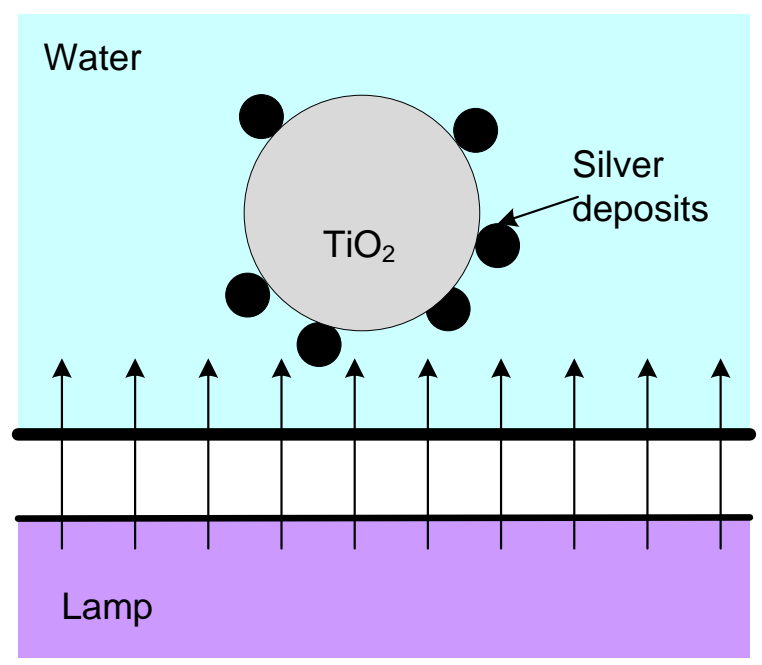

Slurry Reactor

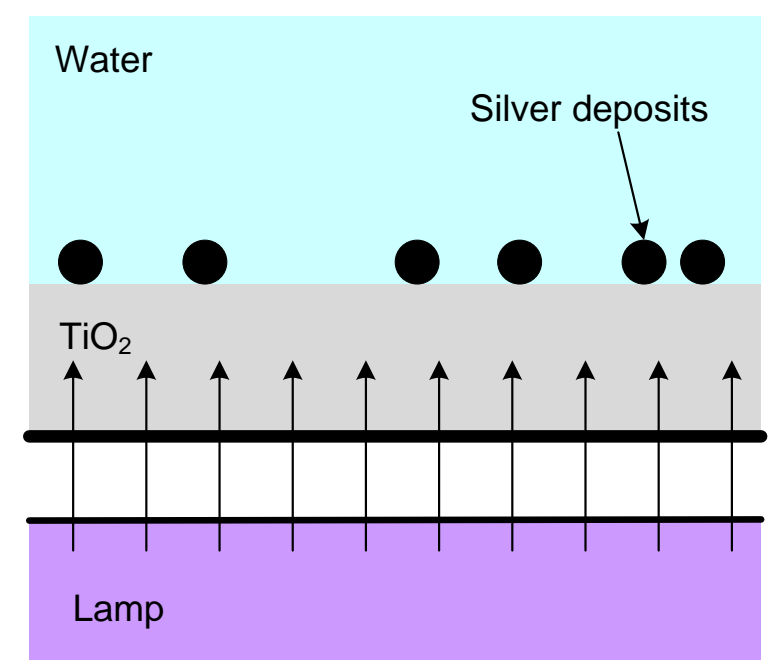

Wall Reactor

Figure 10. Schematic representation of the irradiation patterns in slurry and wall reactors (glass tube width has been omitted for clarity purposes). 


\section{Conclusions}

The potential effect of silver incorporation in the photocatalytic behaviour of titania slurries is overcome by the bactericidal effect of $\mathrm{Ag}$ leached to the solution by reoxidation of the metal particles in the darker regions of the reaction system. A thermal treatment is required to stabilize the silver deposits and reduce the lixiviation of silver to the solution, whose extent is really high for uncalcined materials and for experiments in the dark, suggesting that irradiation is required to stabilize the photoreduced silver clusters in the metallic state.

Experiments of dye photodegradation show a decrease in the activity upon incorporation of silver, what could be produced by a decrease in the absorption of radiation produced by the silver deposits or by a reduction in the adsorption of the dye due to the modification of the $\mathrm{TiO}_{2}$ surface. So, the enhancement in the activity for $E$. coli inactivation could be due to the improvement in the bacterial adhesion to the titania surface or more likely to the direct bactericidal role of silver, and not exclusively to a better electron-hole separation and interfacial charge transfer.

Immobilized $\mathrm{Ag} / \mathrm{TiO}_{2}$ systems in wall reactor configuration has been demonstrated to be optimal from several points of view: i) Silver incorporation increase the activity of the bare $\mathrm{TiO}_{2}$ systems, as result of reduction of the charge carriers recombination, an improvement of the bacterial adhesion and specially of a parallel non-photocatalytic disinfection mechanism based on the toxicity of the silver; ii) the time required to reach the bacterial detection limit is comparable to that of $\mathrm{Ag} / \mathrm{TiO}_{2}$ suspensions; iii) their specific activity per gram of $\mathrm{TiO}_{2}$ is higher than that of slurries or fixed-bed systems; iv) the reactor configuration, with irradiation from the opposite side to the silver modified surface in contact with the solution, maximizes the radiation absorption, reducing simultaneously the lixiviation of silver produced in the darker regions of fixed-bed and slurry systems; and v) the $\mathrm{Ag} / \mathrm{TiO}_{2}$ film is stable, shows no deactivation or lixiviation, and present no inhibition by the organic residuals released after bacterial lysis, allowing the continuous treatment of water. 


\section{Acknowledgements}

The authors gratefully acknowledge the financial support of the Ministerio de Educación y Ciencia of Spain through the program Consolider-Ingenio 2010 (project CSD2006-00044 TRAGUA) and Comunidad de Madrid through the program REMTAVARES S0505/AMB/0395.

\section{References}

[1] G. Becher, Acta Hydrochim. Hydrobiol. 27 (1999) 100-102.

[2] W.J. Huang, G.C. Fang, C.C. Wang, Sci. Total Environ. 345 (2005) 261-272.

[3] S.W. Krasner, H.S. Weinberg, S.D. Richardson, S.J. Pastor, R. Chinn, M.J. Sclimenti, G.D. Onstad, A.D. Thruston, Environ. Sci. Technol. 40 (2006) 7175-7185.

[4] P.R.Gogate, A.B. Pandit, Adv. Environ. Res. 8 (2004) 501-551.

[5] P.R.Gogate, A.B. Pandit, Adv. Environ. Res. 8 (2004) 553-597.

[6] S. Parsons (Ed.) Advanced Oxidation Processes for Water and Wastewater Treatment, IWA Publishing, London, UK, 2004.

[7] C. McCullagh, J.M.C. Robertson, D.W. Bahnemann, P.K.J. Robertson, Res. Chem. Intermed. 33 (2007) 359-375.

[8] J. Blanco-Gálvez, P. Fernández-Ibáñez, S. Malato-Rodríguez, J. Sol Energ. T-ASME, 129 (2007) 4-15.

[9] B. Ohtani, Chem. Lett. 37 (2008) 217-229.

[10] L. Sun, J.R. Bolton, J. Phys. Chem. 100 (1996) 4127-4134.

[11] M.I. Litter, Appl. Catal. B: Environ. 23 (1999) 89-114.

[12] O. Carp, C.L. Huisman, A. Reller, Prog. Solid State Chem. 32 (2004) 33-177.

[13] A. Sclafani, M.N. Mozzanega, J.M. Herrmann, J. Catal., 168 (1997) 117-120.

[14] A. Bansal, S. Madhavi, T.T.Y. Tan, T.M. Lim, Catal. Today, 131 (2008) 250-254.

[15] M.K. Seery, R. George, P. Floris, S.C. Pillai, J. Photochem. Photobiol. A:Chem., 189 (2007) 258-263.

[16] M. Sökmen, F. Candan, Z. Sumer, J. Photochem. Photobiol. A:Chem. 143 (2001) 241-244.

[17] K.D. Kim, D.N. Han, J.B. Lee, H.T. Kim, Scripta Mater. 54 (2005) 143-146. 
[18] A. Kubacka, M. Ferrer, A. Martínez-Arias, M. Fernández-García, Appl. Catal. B:Environ. 84 (2008), 87-93.

[19] M. Sökmen, S. Degerli, A. Aslan, Exp. Parasitol. 119 (2008) 44-48.

[20] Q. Li, S. Mahendra, D.Y. Lyon, L. Brunet, M.V. Liga, D. Li, P.J.J. Alvarez, Water Res 42 (2008) 4591-4602.

[21] J. Marugán, M.J, López-Muñoz, J. Aguado, R. van Grieken, Catal. Today 124 (2007) 103-109.

[22] J. Marugán, M.J. López-Muñoz, R. van Grieken, J. Aguado, Ind. Eng. Chem. Res. 46 (2007) 7605-7610.

[23] R. van Grieken, J. Marugán, C. Sordo, C. Pablos, Catal. Today 144 (2009) 48-54.

[24] K. Page, R.G. Palgrave, I.P. Parkin, M. Wilson, S.L.P. Savin, A.V. Chadwick, J. Mater. Chem. 17 (2007) 95-104.

[25] J. Marugán, R. van Grieken, C. Sordo, C. Cruz, Appl. Catal. B:Environ. 82 (2008) 2736.

[26] B. Li, B.E. Logan, Colloid Surface B:Biointerfaces 36 (2004) 81-90.

[27] D. Gumy, C. Morais, P. Bowen, C. Pulgarín, S. Giraldo, R. Hajdu, J. Kiwi, Appl. Catal. B: Environ. 63 (2006) 76-84.

[28] G. Gogniat, M Thyssen, M. Denis, C. Pulgarín, S. Dukan, FEMS Microbiol. Lett. 258 (2006) 18-24.

[29] N.R.C. Fernandes Machado, V.S. Santana, Catal. Today 107-108 (2005) 595-601.

[30] M. Nasr-Esfahani, M.H. Habibi, Int. J. Photoenergy, Article ID 628713, (2008).

[31] H. Tran, J. Scott, K. Chiang, R. Amal, J. Photochem. Photobiol. A:Chem. 183 (2006) 41-52.

[32] V. Vamathevan, R. Amal, D. Beydoun, G. Low, S. McEvoy, Chem. Eng. J. 98 (2004) 127-139.

[33] H. Czili, A. Horváth, Appl. Catal. B:Environ. 89 (2009) 342-348.

[34] H.M. Sung-Suh, J.R. Choi, H.J. Hah, S.M. Koo, Y.C. Bae, J. Photochem. Photobiol. A:Chem. 163 (2004) 37-44. 